OPEN ACCESS

Edited by:

Bing Han,

Peking University School and Hospital

of Stomatology, China

Reviewed by:

$\mathrm{HaO} \mathrm{Hu}$,

Qingdao University, China

Payam ZarrinTaj,

Oklahoma State University,

United States

Xun Sun,

Tianjin Hospital, China

*Correspondence:

Xing Wang

wangxing@iccas.ac.cn

Rui Chen

chenruiwal@smmu.edu.cn

Xiaojian Ye

xjyespine@smmu.edu.cn

${ }^{\dagger}$ These authors have contributed equally to this work

Specialty section:

This article was submitted to Biomaterials,

a section of the journal

Frontiers in Bioengineering and

Biotechnology

Received: 27 July 2020

Accepted: 24 August 2020

Published: 17 September 2020

Citation:

Tang G, Tan Z, Zeng W, Wang $X$, Shi C, Liu Y, He H, Chen R and Ye $X$

(2020) Recent Advances

of Chitosan-Based Injectable

Hydrogels for Bone and Dental Tissue

Regeneration

Front. Bioeng. Biotechnol. 8:587658.

doi: 10.3389/fbioe.2020.587658

\section{Recent Advances of Chitosan-Based Injectable Hydrogels for Bone and Dental Tissue Regeneration}

\author{
Guoke Tang ${ }^{1,2,3 t}$, Zhihong Tan't, Wusi Zeng ${ }^{2}$, Xing Wang ${ }^{4,5 *}$, Changgui Shi', Yi Liu', \\ Hailong $\mathrm{He}^{1}$, Rui Chen ${ }^{1 *}$ and Xiaojian $\mathrm{Ye}^{1,3 *}$ \\ ${ }^{1}$ Department of Orthopedic Surgery, Changzheng Hospital, Second Military Medical University, Shanghai, China, \\ ${ }^{2}$ Department of Spine Surgery, The Affiliated Zhuzhou Hospital of Xiangya School of Medicine, Central South University \\ (CSU), Hunan, China, ${ }^{3}$ Department of Orthopedics, Tongren Hospital, Shanghai Jiao Tong University School of Medicine, \\ Shanghai, China, ${ }^{4}$ Beijing National Laboratory for Molecular Sciences, Institute of Chemistry, Chinese Academy of Sciences, \\ Beijing, China, ${ }^{5}$ University of Chinese Academy of Sciences, Beijing, China
}

Traditional strategies of bone repair include autografts, allografts and surgical reconstructions, but they may bring about potential hazard of donor site morbidity, rejection, risk of disease transmission and repetitive surgery. Bone tissue engineering (BTE) is a multidisciplinary field that offers promising substitutes in biopharmaceutical applications, and chitosan (CS)-based bone reconstructions can be a potential candidate in regenerative tissue fields owing to its low immunogenicity, biodegradability, bioresorbable features, low-cost and economic nature. Formulations of CS-based injectable hydrogels with thermo/pH-response are advantageous in terms of their highwater imbibing capability, minimal invasiveness, porous networks, and ability to mold perfectly into an irregular defect. Additionally, CS combined with other naturally-derived or synthetic polymers and bioactive agents has proven to be an effective alternative to autologous bone and dental grafts. In this review, we will highlight the current progress in the development of preparation methods, physicochemical properties and applications of CS-based injectable hydrogels and their perspectives in bone and dental regeneration. We believe this review is intended as starting point and inspiration for future research effort to develop the next generation of tissue-engineering scaffold materials.

Keywords: chitosan, injectable hydrogel, responsiveness, bone repair, dental tissue regeneration

\section{INTRODUCTION}

Bone, composed of collagen and calcium phosphate apatite crystals, is a well-known internal support system in higher vertebrates, which provides the rigidity, strength and a certain degree of elasticity to the living body. In recent years, on account of the increase of population aging, accidental injury, disease, trauma, obesity and weak physical activity in internal and external

Abbreviations: ACP, amorphous calcium phosphate; ALN, alendronate; ASP, aspirin; BCP, biphasic calcium phosphate; $\beta$-GP, $\beta$-sodium glycerophosphate; bFGF, basic fibroblast growth factor; BMPs, morphogenetic proteins; BMP2, bone morphogenetic protein 2; BMP-7, bone morphogenetic protein-7; BTE, bone tissue engineering; $\mathrm{CMCh}$, carboxymethyl chitosan; CS, chitosan; DPSCs, dental pulp stem cells; ECM, extracellular matrix; EPO, erythropoietin; GP, $\beta$-glycerophosphate; MCS, maleilated chitosan; MSCs, mesenchymal stem cells; NIPAAm, N-isopropylacrylamide; NPs, nanoparticles; nBG, bioactive glass NP; ORN, ornidazole; PEGDA, poly(ethylene glycol) diacrylate; PVA, poly(vinyl alcohol); VEGF, vascular endothelial growth factor. 
mediators, bone disorders and diseases are on the rise worldwide (Amin et al., 2014; Saravanan et al., 2016; Baldwin et al., 2019; Wang et al., 2019; Yu et al., 2020). Although natural curing is a stable and reliable process, Patients with bone traumas always suffer from impaired healing and rehabilitation. Traditional healing strategy includes the autografts, allografts and xenografts that are employed as bone substitutes to promote bone repair. However, these grafts have many disadvantages in repetitive manipulation process, high cost, surgery wound, immune rejection and potential infectious diseases (Visser et al., 2019). The advent of Bone Tissue Engineering (BTE) brings about the advanced development of bone regeneration at the defect host site without any post-operative complications (e.g., morbidity and immunogenicity). BTE is structured around four key components: (1) osteoblasts generate a bone tissue matrix; (2) biocompatible backbone mimic the extracellular matrix (ECM); (3) vascularization process offer nutrients and wastes transport and (4) morphogenesis signals guide the cell activation (Amini et al., 2012; Guo and Ma, 2014). Thereby, bone tissue engineering material requires favorable properties (e.g., osteoinduction and osseointegration), which can promote the progenitor cell differentiation to osteoblasts, support bone growth and facilitate bone fusion to form new bone tissue. In addition, BTE materials should have chemical and mechanical stabilities, nonthrombosis, easy sterilization and facile manufacturability in the host environment. For example, alveolar bone defects are urgently needed to be regenerated by relying on the advanced BTE materials to bring about a positive impact on dental tissue engineering for the periodontal therapy (Hench and Polak, 2002; Stevens, 2008).

Natural polymers with good biocompatibility and biodegradability have a variety of characteristics and advantageous properties for living tissues and cells ( $\mathrm{Li}$ et al., 2020a). As a representative, chitosan (CS), deacetylated form of chitin (Figure 1), is a naturally linear cationic heteropolymer extracted from the shrimp or crab shells. It has analogous compositions and structures to glycosaminoglycans, and renders high biocompatibility, good biodegradability and minimal immune response to tissues and cells (Kavya et al., 2013; Ran et al., 2016; Yang et al., 2016; Atak et al., 2017; Keller et al., 2017). Its physical properties are mainly relied on the molecular weight, degree of deacetylation and purity (Ngo and Kim, 2014). For example, owing to the cationic attribute, CS possesses outstanding antimicrobial activity against both Gram-positive and Gram-negative bacteria, which is relied on the type and degree of deacetylation of chitosan as well as the other extrinsic environmental conditions, but its antimicrobial mechanism has not yet been fully understood. Due to the presence of protonated amino groups of the D-glucosamine residues (Figure 1A), CS can form a non-Newtonian, shear-thinning fluid in most diluted acidic solutions at a $\mathrm{pH}$ below 6.5 (pKa value $\sim 6.3$ ), and further contributes to the complexes with metal ions, polymers, lipids, proteins, DNA, etc. (Berillo et al., 2012, 2014; Zhou et al., 2015; Saravanan et al., 2016; Berillo and Cundy, 2018; Yang et al., 2018; Liu H.Y. et al., 2020). In addition, CS-based hydrogels can be chemically crosslinked by glutaraldehyde, oxidized dextran or other carbohydrates and genipin due to the reductive amination between the amino and aldehyde groups in mild conditions (Berillo et al., 2012; Akilbekova et al., 2018; Lu et al., 2018; Chen et al., 2019). Although CS hydrogel has many advantages, its mechanical properties are weak. Thus, it should be combined with other functional materials to promote the osteogenic differentiation and tissue regeneration (Deepthi et al., 2016; Saravanan et al., 2016; Bao et al., 2020).

\section{CS-BASED HYDROGELS}

Hydrogel has a three-dimensional porous and interconnected structure that can create a biocompatible ECM microenvironment for cell attachment and proliferation, which can be served as a potential bone supportive system to enhance remodeling at defect sites (Ko et al., 2013; Liu et al., 2017; Wang et al., 2017a, 2020b; Xu et al., 2020a,b). On account of the long and painful invasive surgery for the clinical application of implanted hydrogels, injectable hydrogels are required to have capacities to fill irregularly shaped defects in a non-invasive way, which are recognized as a high-quality and less invasive alternative surgical strategy in BTE (Li et al., 2020b). When the precursor solution containing drugs, cells and/or biomolecules is injected into the subcutaneous region of defective site, composite hydrogels can be quickly formed via the physically or chemically crosslinking reaction with close correlations to the surrounding environments (Yang J.A. et al., 2014; Cao et al., 2018; Wang et al., 2018a; Bao et al., 2019; Liu B.C. et al., 2020). Especially, CS-based injectable hydrogels can be actuated by physical or chemical stimuli via the sol-gel transition. Besides, CS-based injectable hydrogels can deliver cells, drugs and other bioactive molecules, and thus receiving an amount of recognition in fields of cosmetics, food, drug/gene delivery and bone regeneration (Figure 1B; Zheng et al., 2010; Vo et al., 2016; Menon et al., 2018; Yang et al., 2018; Lavanya et al., 2020).

\section{Preparation Techniques of CS-Based Hydrogels}

Hydrogels are generally fabricated via crosslinking the polymer network through physical and chemical strategies. Based on these two basic approaches, there are various preparation techniques for construction of hydrogel configurations. On the one hand, physical crosslinkers mainly include the hydrophobichydrophobic, host-guest, ionic or electrostatic, crystallization and stereo complex interactions, which can cause the formation of polymer network in mild conditions (Hoffman, 2012; Sivashanmugam et al., 2015; Fan et al., 2019; Zhu C.X. et al., 2019; Wang et al., 2020a). Physically crosslinked hydrogels possess great advantages in biological applications because of the absence of chemical crosslinkers that may bring about the unpredictable and potential toxicity for the tissues, but their reversible architectures, poor stability and low mechanics greatly limited the scope of applications (Zhang et al., 2013; Maitra and Shukla, 2014; Parhi, 2017; Li et al., 2018). On the other hand, chemical crosslinkers are constructed by the covalent linkage of polymer chains together within the network using high-effective synthetic methods, such as click chemistry, Schiff base reaction, 


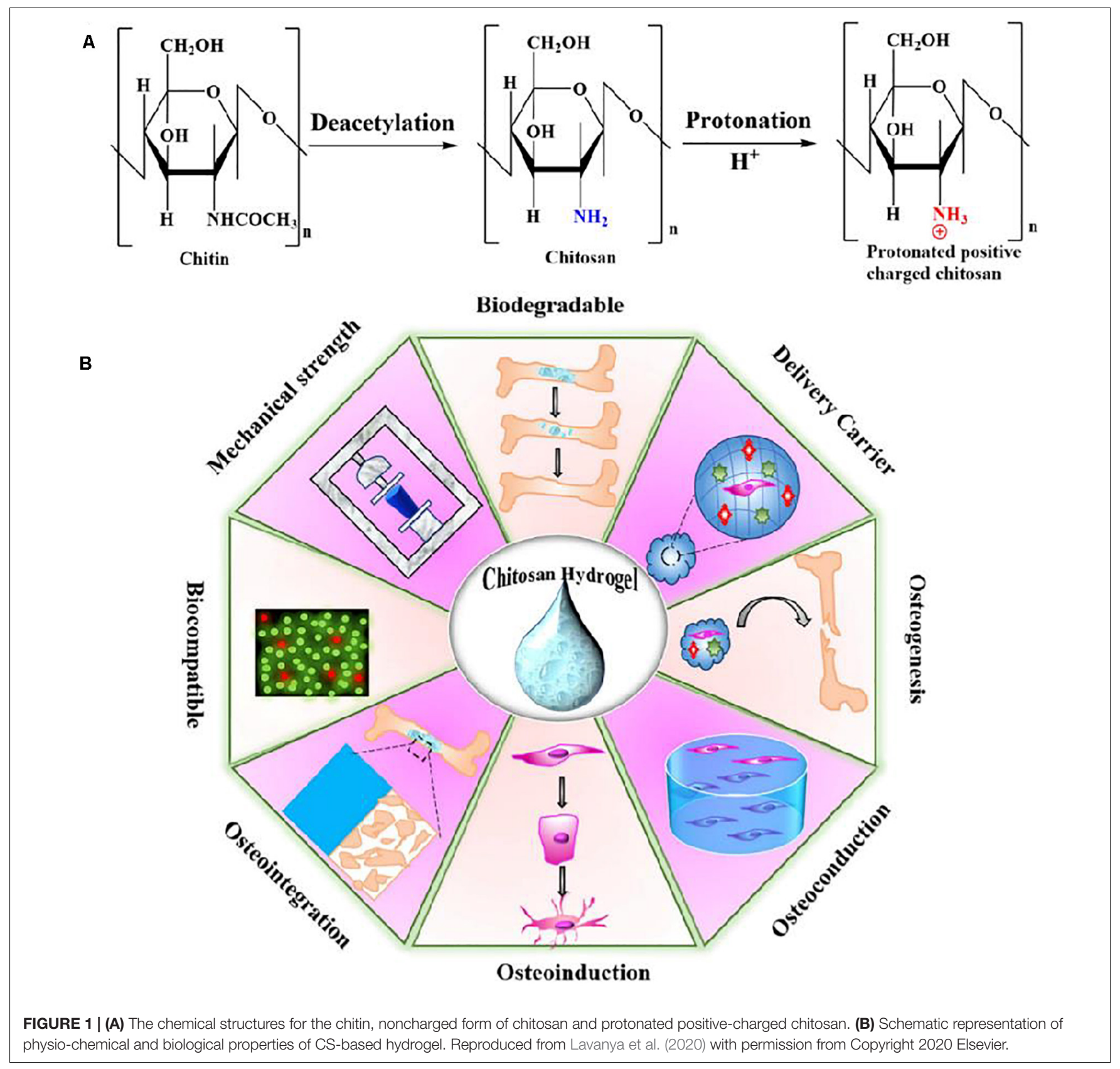

free radical polymerization, etc. (Hennink and van Nostrum, 2012; Wang et al., 2013; Zhang J.F. et al., 2019). On account of the permanent and irreversible junctions among polymeric chains, chemically crosslinking hydrogels possess stable structures and excellent mechanics for tissue engineering fields. However, toxic chemical agents and difficult sterilization may produce adverse effects and certain insecurities.

\section{Physico-Chemical Properties of CS-Based Injectable Hydrogels}

In recent years, the application of injectable in-situ forming hydrogels in orthopedics has been widely investigated by many scientists (Gyawali et al., 2013). Unlike the prefabricated stents that require surgical implantation, injectable hydrogels can be in situ injected into the defect sites to fill in any geometric deformities using the minimally invasive surgery methods. Hydrogel is usually used for confronting bone defects in nonweight bearing parts or injured bone tissue through delivering and releasing the therapeutic biomolecules and agents once the stimulus response that triggers its physical and/or chemical properties has been changed. On account of numerous hydroxy and amine groups within the cationic CS framework, CS can be feasibly modified to improve its multifunction, such as antibacterial property, solubility, stimulus-response, adhesion and degradation behaviors (Lavanya et al., 2020). Therefore, 
CS-based injectable hydrogels possess more advantages on the tailor of topological structures, biodegradability behaviors, cytocompatibility and adhesive force, which can be widespread used as effective biopharmaceutical materials to promote bone regeneration (Liu et al., 2017; Shariatinia and Jalali, 2018).

Chitosan is usually combined with other natural-derived or synthetic biomaterials via the covalent and/or non-covalent bonds, yielding a varied of multifunctional hydrogels. Wherein, physical gelation is a typical approach for fabrication of CS-based hydrogels with good biocompatibility and gradual degradability to promote the cell-materials interactions and stimulate the proliferation and differentiation of osteoprogenitor cells (Berger et al., 2004). Therefore, development of CS-based injectable hydrogels would allow for the effective therapy for the bone regeneration, especially for the irregular defective sites of bone tissue. Based on this physical gelation of CS-based injectable hydrogel, environmentally responsive injectable hydrogels, such as $\mathrm{pH}$, light and temperature, are widely used for repair of large bone defect, because an externally applied trigger for gelation can easily tailor sol-gel transition with the facile permeation into the defect sites and quick gelation in situ to fully seal the injury. Recently, Li et al. (2015) prepared a series of soluble UVcrosslinkable CS-based injectable hydrogels by modification of amine groups of CS with methacrylic anhydride in the absence of any activators. These methacryloyl groups improved the CS solubilization in water by impairing intra-/intermolecular hydrogen bonds and provided the crosslinkable CS derivatives. Xia et al. (2017) reported a photopolymerized injectable water-soluble maleilated chitosan (MCS)/poly(ethylene glycol) diacrylate (PEGDA) hydrogels, which had faster gelation rate, higher compressive strength than MCS hydrogel under UV radiation. Control of the MCS/PEGDA ratio could tailor the swelling behavior and mechanical properties of composite hydrogels that could promote the L929 cells attachment and tissue regeneration. Instead of UV light, $\mathrm{Hu}$ et al. (2012) prepared CS hydrogels crosslinked under visible light for tissue engineering. By tailoring three various blue light initiators (camphorquinone, fluorescein and riboflavin), methacrylate glycol CS can form the CS hydrogels under the visible light (400-500 $\mathrm{nm}$ at $500 \mathrm{~mW} \mathrm{~cm}^{-2}$ ), displaying good mechanical properties and less damages to cells than energetic UV light. Further, diverse therapeutic agents or drugs can be encapsulated into these temperature and $\mathrm{pH}$-responsive injectable hydrogels to form the multifunctional hydrogels in tissue engineering and drug delivery systems. For example, Qi et al. (2013) incorporated the bone morphogenetic proteins (BMPs) and mesenchymal stem cells (MSCs)/osteoprogenitors into CS-based injectable hydrogels. The thermo-sensitive CS/poly (vinyl alcohol) (PVA) composite hydrogel can offer the strength support and tailored degradation time, which induced the tissue repair via the space conduction and occupation of defect part. In addition, compared to the pure CS hydrogel, introduction of non-degradable PVA could obviously postpone the degradation and prolong the selfhealing term of tissue within the defect center.

Besides, rheological properties also play vital roles in injectable CS-based hydrogels, especially for the gelation, firmness and durability of crosslinking network, which provide intriguing guidance on the effective selection of appropriate chitosan for wide application. Many studies on rheological properties of chitosan in solution have been conducted to characterize the effects various parameters such as polymer concentration, degree of deacetylation, concentrated chitosan, chitosan and vinyl polymers, temperature, shearing and storage time, and addition of other polymers/nanoparticles on the viscoelastic behaviors, which are closely relative to a peculiar mechanism of association with the double-chain strands connected network (Hwang and Shin, 2000; Chen et al., 2003; Martiínez et al., 2004; Lewandowska, 2009; El-hefian and Yahaya, 2010; Racine et al., 2017). Until now, injectable hydrogels are widely applied for tissue engineering and orthopedic applications. Unlike surgical implantation methods, pre-fabricated hydrogel can be injected into any geometries of defect bearing sites using minimally invasive procedures and quick in situ gelation through a sol-gel transition once exposure to a simulative change. In addition, injectable hydrogels can also be blended with other biomolecules, therapeutic agents and cells to form multifunctional carriers to repair the bone and dental tissues (Figure 2; Saravanan et al., 2019).

\section{pH-Responsive CS-Based Injectable Hydrogels}

Chitosan and its derivatives are a series of natural biopolymers with good biocompatibility, $\mathrm{pH}$ sensitivity, enzymatic biodegradability and polycationic attributes. Especially, tailor the protonation/deprotonation of $-\mathrm{NH}_{2}$ group can obviously furnish CS-based injectable hydrogels with $\mathrm{pH}$-responsive behaviors (Xu and Matysiak, 2017). Lower $\mathrm{pH}$ can protonate amine group to induce the electrostatic repulsion, and thus the polymer chains can easily expand and interact with water molecules to effectively improve the water-solubility. In contrast, higher $\mathrm{pH}$ can deprotonate the $-\mathrm{NH}_{2}$ group and cause the collapse of globular structure, severely impairing the water-solubility of CS. In this case, the water solubility and swelling property of CS-based hydrogels is mainly relied on the its $\mathrm{pKa}$ value and external pH conditions (Rizwan et al., 2017). Therefore, CS-based injectable hydrogels possess the innate $\mathrm{pH}$ response that has been attracted considerable attentions in the bone regeneration process. In addition, incorporation of various polymers with CS can improve this $\mathrm{pH}$ responsiveness. Nevertheless, CS has poor solubility in alkaline and neutral solutions as well as the insufficient mechanical performance. To overcome these limitations, various physical or chemical modification strategies have been well-developed to make CS soluble without impairing its other properties.

For instance, Rogina et al. (2017) demonstrated a pHresponsive CS-hydroxyapatite hydrogel with a gelling agent of $\mathrm{NaHCO}_{3}$. Tailoring of $\mathrm{NaHCO}_{3}$ can achieve the quick gelation of CS-hydroxyapatite-based hydrogel within $4 \mathrm{~min}$, which exhibited good viability for cell proliferation and differentiation as a potential cell carrier. Zhao et al. (2019) developed a composite CMCh-ACP hydrogel via combining the carboxymethyl chitosan (CMCh) and amorphous calcium phosphate (ACP). Incorporation of an acidifier of glucono $\delta$-lactone could endow $\mathrm{pH}$-responsive injectable hydrogels with 


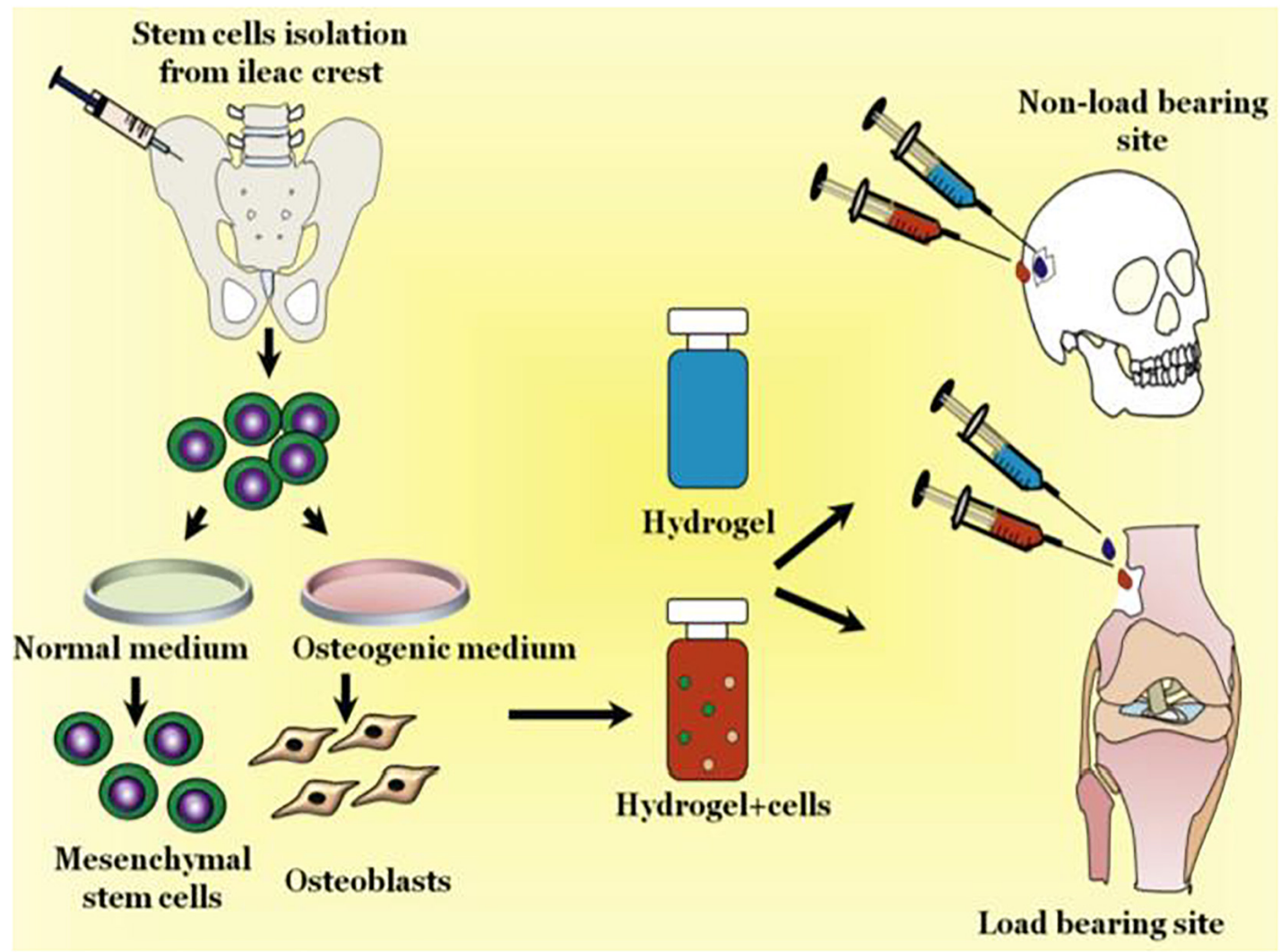

FIGURE 2 | Schematic representation of injectable hydrogels for treating bone loss at defective sites. Reproduced from Saravanan et al. (2019) with permission from Copyright 2019 Elsevier.

good biocompatibility and effective cell adhesion/proliferation, which upregulated the expression of bone markers and enhanced the new bone regeneration (Figure 3).

\section{Thermo-Responsive CS-Based Injectable Hydrogels}

Chitosan itself has not thermosensitive behaviors, and thermoresponsive CS-based hydrogels are generally fabricated via introducing the thermo-responsive polymers into CS-based hydrogels (Argüelles-monal et al., 2018). In views of simple regulation and easy utilization for in vitro and in vivo testing, temperature is recognized as a typical stimulus for the hydrogel system. In recent years, ideally thermoresponsive CS injectable hydrogels with the sol-gel transition at a physiological temperature have been developed in application of tissue engineering because of their temperature response, attractive moldable ability, tailorable rheological property, excellent biocompatibility and biodegradability to the cells and tissues, which can provide suitable manipulation and enhance cellular activity for bone and dental regenerations. In addition, encapsulation of diverse polymers (natural and synthetic polymers), bioactive molecules and nanoparticles can also expand the functional properties of CS injectable hydrogels for biomedical applications (Mohebbi et al.,
2019; Zarrintaj et al., 2019; Bagheri et al., 2020; Khalili et al., 2020; Mahmodi et al., 2020; Nourbakhsh et al., 2020). For example, CS/ $\beta$-glycerophosphate (GP) hydrogel is a famous scaffold for wide-range delivery of growth factors, cells, small drugs and nucleic acid. Since cationic CS chains can be connected with negatively charged GP molecules via the electrostatic attraction and hydrogen bonds, injectable CS/GP hydrogels can achieve structural optimization systems with a sol-gel transition temperature of $37^{\circ} \mathrm{C}$ for the bone regeneration (Figure 4; Dhivya et al., 2015; Saravanan et al., 2019).

The gelation mechanism of this thermo-responsive CS/GP hydrogel has been detailedly elucidated as follows (Chenite et al., 2001). Firstly, on account of poor solubility of CS in neutral and basic solutions, CS solutions above $\mathrm{pH} 6.2$ can result in the immediate formation of hydrated gel-like precipitate as well as the occurrence of phase separation of CS at $\mathrm{pH}>6$ to form a hydrogel. Maintaining CS solution within a physiological $\mathrm{pH}(6.8-7.2)$ in the presence of GP polyol salt could generate a thermo-responsive injectable hydrogel, which kept a sol state at room temperature and transferred into a gel state at physiological temperature (cloud point of $\geq 37^{\circ} \mathrm{C}$ ). Incorporation of GP components into CS solutions can reduce electrostatic repulsion between phosphate groups of GP and amino groups of CS, enhance CS-CS hydrophobic interactions 

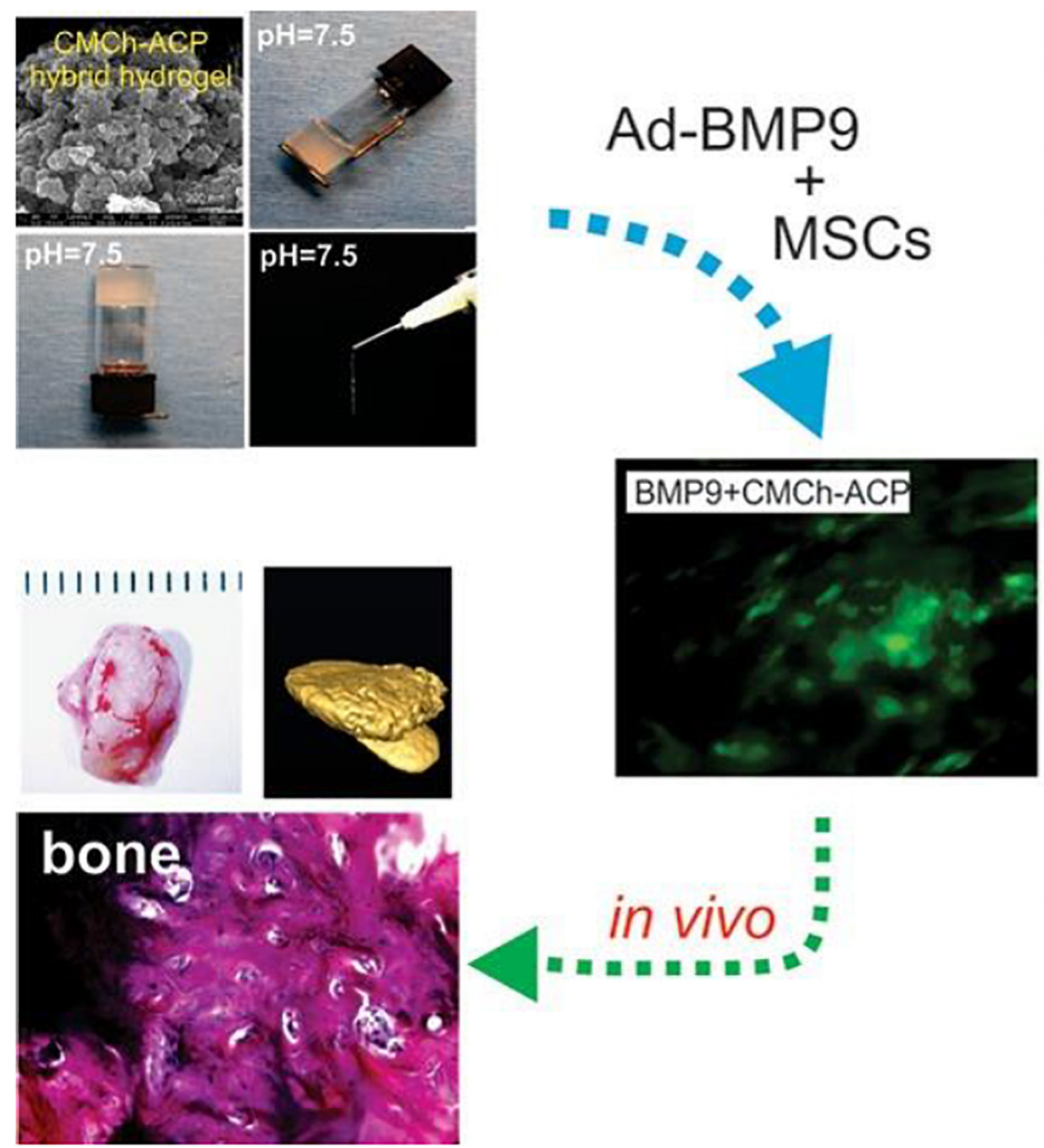
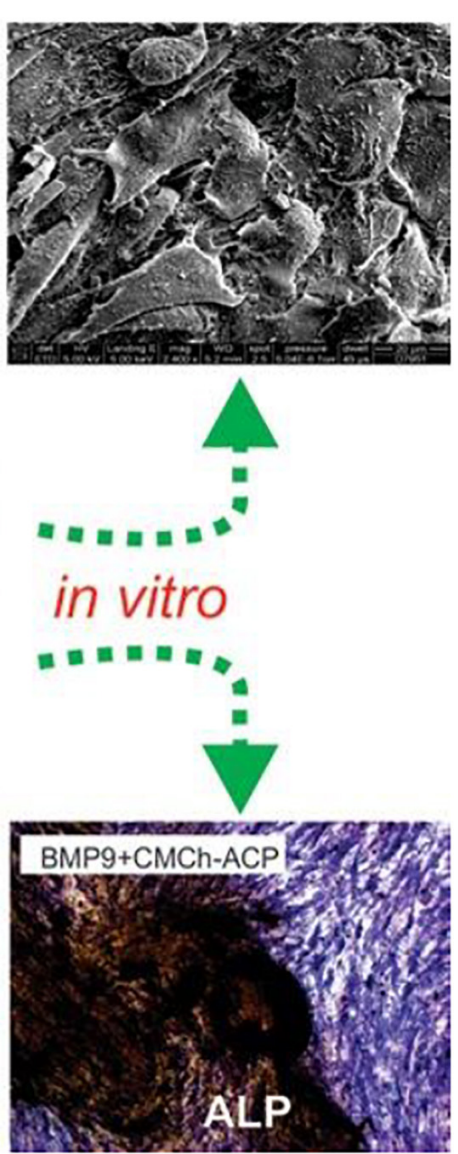

FIGURE 3 | Schematic representation of pH-responsive CS-based hydrogels for bone tissue engineering. Reproduced from Zhao et al. (2019) with permission from Copyright 2019 American Chemical Society.

and increase hydrogen bonding effects between CS chains during gel formation, and therefore the $\mathrm{pH}$ range can be modulated from 7.0 to 7.4 and the sol-gel transition temperature can be tailored at $37^{\circ} \mathrm{C}$. The temperature dependence of CS/GP hydrogels has been investigated by the rheological studies. Owing to the hydrophobic interactions between CS chains and glycerol groups, CS chains aggregation can be prevented by the CS-water interactions at low temperature. Once upon heating, water molecules are partially removed from the glycerol moieties and CS chains can associate and aggregate into a gel formation. In this CS/GP gelling system, temperature rise can also tailor CS-CS hydrophobic interactions in addition to the regulation of electrostatic forces, because the orientation of dipolar water molecules surrounding CS polymer chains is effectively limited via increasing the vibrational and rotational energy of water molecules. These energized water molecules are removed around the CS polymeric chains, thereby causing the interconnection among dehydrated hydrophobic segments. At low temperatures, CS displays a helical structure due to the presence of intramolecular hydrogen bonds and the masking of physical connections. At high temperature, the decreasing number of intramolecular hydrogen bonds allows the CS molecules to unfold and facilitate the gelation. Thus, $\mathrm{pH}$ and temperature are significantly important factors for this thermoresponsive CS/GP injectable hydrogels.

\section{Polymers Introducing the CS-Based Injectable Hydrogels}

Incorporation of various polymers like naturally-derived (e.g., alginate, hyaluronic acid, collagen, starch, and silk fibroin) and synthetic macromolecules [e.g., poly(vinylalcohol), polyethylene glycol and polycaprolactone] into CS hydrogels can further improve their multifunctionality and thermo-responsive behaviors for effective bone repair. For example, Bagheri et al. (2019) prepared a kind of electroactive hydrogel based on chitosan-aniline oligomer and agarose, wherein the aniline oligomer can tailor the swelling, degradation rate, thermal and conductive properties of CS-based hydrogels. Owing to its conductivity, control of the electrical stimulus can manipulate the on-demand drug release that may promote the cell activity, growth and proliferation. Chen et al. (2013) prepared a biocompatible injectable thermo-responsive HA-CPN/BCP hydrogel based on a hyaluronic acid-g-chitosan-g-poly (Nisopropylacrylamide) containing biphasic calcium phosphate (BCP) ceramic microparticles. The HA-CPN/BCP possessed better biocompatibility with human fetal osteoblast cell 

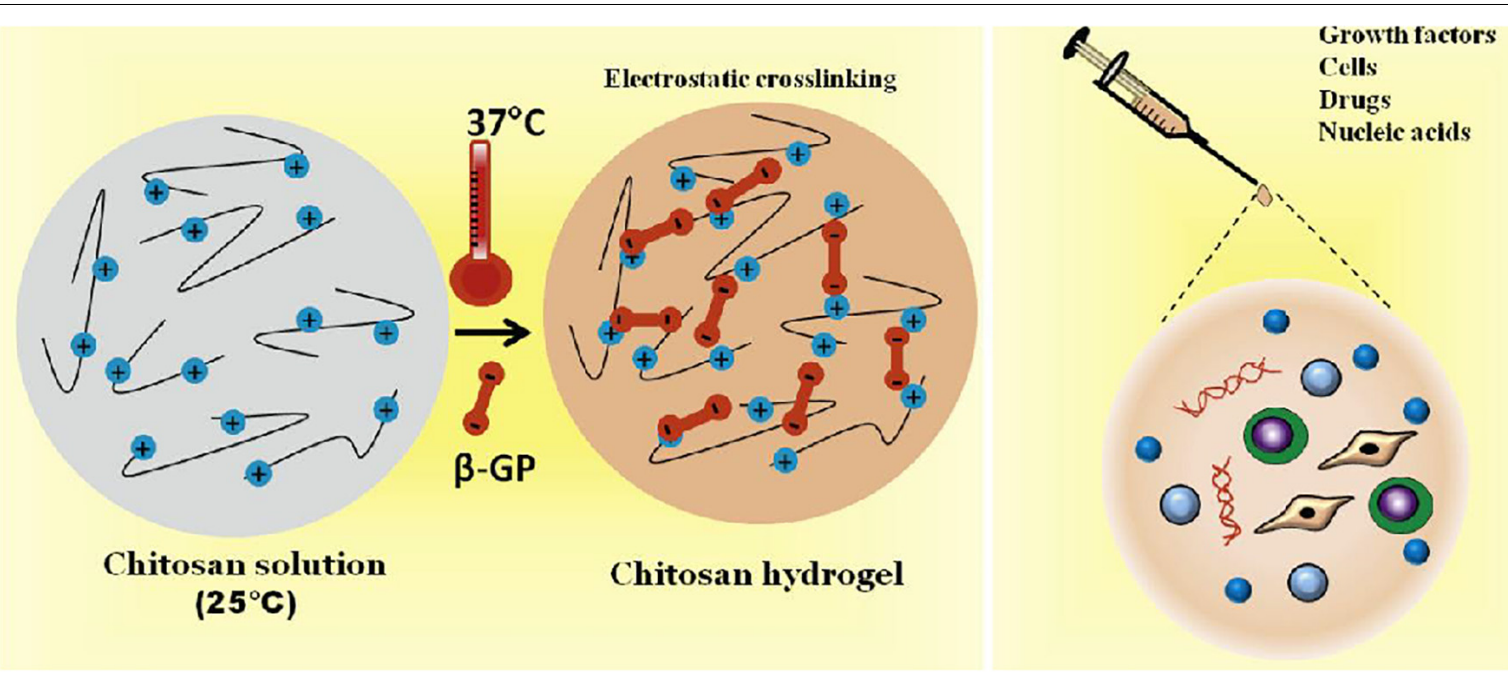

FIGURE 4 | Schematic representation of thermal-responsive CS/ $\beta$-GP hydrogels encapsulating with various growth factors, cells, drugs and nucleic acids for bone tissue engineering. Reproduced from Saravanan et al. (2019) with permission from Copyright 2019 Elsevier.

attachment, proliferation and osteoblastic differentiation. In addition, higher mechanical strength and elasticity of these thermo-responsive injected hydrogels was benefited for calcium deposition, extracellular matrix mineralization and generation of ectopic bone tissue. Additionally, incorporation of synthetic polymers endows the CS hydrogels with multifunction to achieve the advanced regulation. Wu et al. (2018) constructed a thermosensitive NIPAAm-g-CS hydrogel with disulfide crosslinkers throughout the networks (Figure 5), and found that three types of cells exhibited excellent biocompatibility with favorable cell attachment, growth and proliferation.

\section{Bioactive Molecules Encapsulated CS-Based Injectable Hydrogels}

Over the last decade, CS-based hydrogels have been functionalized via loading bioactive molecules into drug delivery systems, compelling the bioactive molecules to locally deliver into target sites with adequate dose for a desired period. Encapsulation of hydrophobic and hydrophilic molecules like bioactive factors, drugs, proteins, amino acid, and nucleic acids into CS-based responsive hydrogels can construct smart delivery system and bone regenerative medicine. Wherein, these bioactive molecules [e.g., bone morphogenetic protein 2 (BMP-2) and vascular endothelial growth factor (VEGF)] can keep long stability and half-life with low adverse effects while thermo-responsive injectable hydrogels can effectively prolong the localized drug or growth factor release in a sophisticated delivery system (Tiffany et al., 2012; Faikrua et al., 2014; Mi et al., 2017). In this case, these bioactive molecules-encapsulated CSbased hydrogels can modulate and promote cell differentiation, proliferation, migration, recruitment and angiogenesis. For example, Li et al. (2017) demonstrated a thermo-responsive CS/CSn (pDNA-BMP2)-GP hydrogel system of CS-based hydrogel with pDNA-BMP2 for alveolar bone regeneration. The sustained release of pDNA-BMP2 could affect the osteocytes growth within the lacunae, increase trabecular thickness and promote trabecular bone formation. Apart from these growth factors, CS-based hydrogels could deliver bone resorption inhibitors of alendronate (ALN) to treat the Paget's disease and osteoporosis. Nafee et al. (2017) prepared ALN-loaded $\mathrm{CS} / \beta$-GP hydrogel with injectable and thermo-reversible gelation behaviors. These biodegradable and biocompatible hydrogels expressed less inflammatory responses and faster proliferation of granulation tissue via controlling ALN drug release for 65 days.

\section{Nanoparticles Encapsulated CS-Based Injectable Hydrogels}

Incorporation of functional nanoparticles (NPs) into hydrogels can increase the mechanical, biological, and chemical properties and therefore expand their applications. Especially, metal/metaloxide NPs (e.g., $\mathrm{Au}, \mathrm{Ag}$, and $\mathrm{Fe}_{3} \mathrm{O}_{4}$ ), inorganic/ceramic NPs (e.g., hydroxyapatite, calcium phosphate, silica and silicates), and polymeric NPs (natural/synthetic polymers, dendrimers and hyperbranched polyesters) can promote the osteogenic differentiation and mineralization for bone regeneration (Moorthi et al., 2014; Wang et al., 2014, 2016, 2017b, 2018b; Yang Y.Y. et al., 2014; Yang et al., 2015, 2021; Thoniyot et al., 2015; Ko et al., 2018; Min et al., 2018; Bian et al., 2020; Fan et al., 2020). For example, Radwan et al. (2020) prepared CS-based calcium phosphate composite scaffolds with embedded moxifloxacin hydrochloride. Composite hydrogels delivered the antibiotic drugs for 3 days and induced the cell differentiation and osteoblasts proliferation, benefiting for bone tissue formations using the osteomyelitis-induced animal model. Moreira et al. $(2018,2019)$ constructed a novel thermo-responsive CS/gelatin/nBG-based composite hydrogel by combining CSgelatin with bioactive glass NP (nBG), on account of its capacity to bond with living tissues, these thermo-responsive composite hydrogels possessed enhanced osteoblasts proliferation and angiogenesis-related gene expressions, thus promoting cell 


\section{A

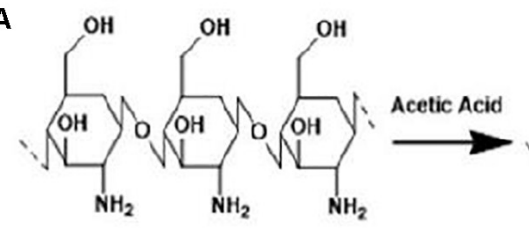 Chitosan

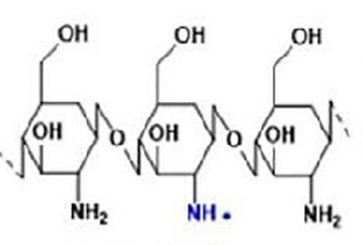 \\ Radical Chitosan

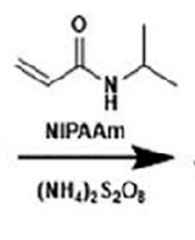

B
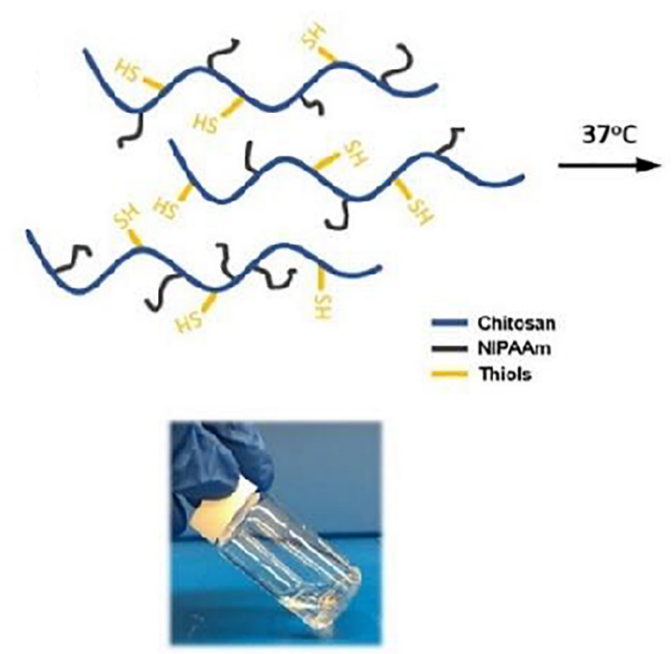

(1) 


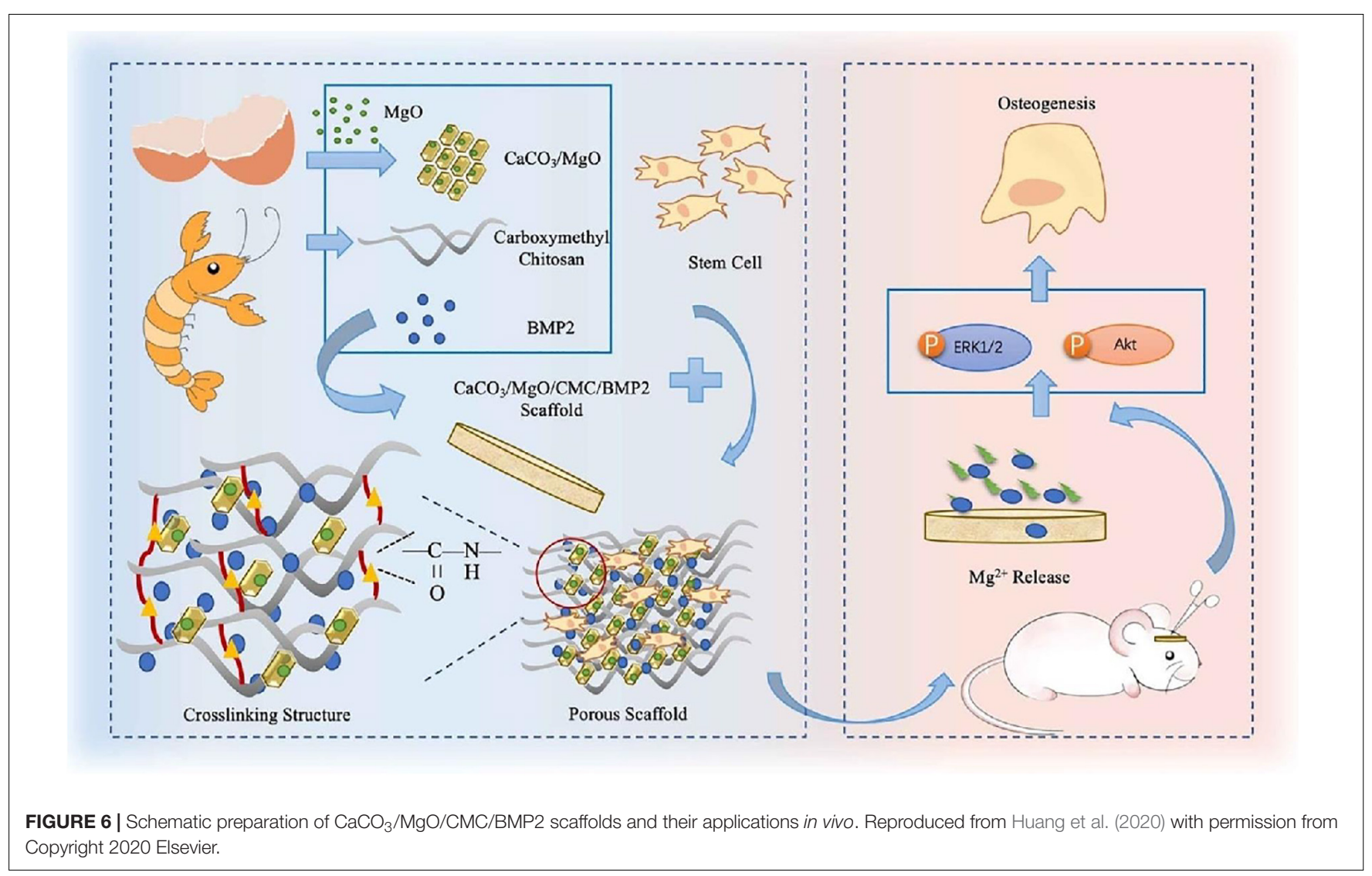

these functional DN hydrogels with great potentials for stem cell therapy and tissue engineering application. It is noted that tunable osteogenesis and degradation rates are important for repairing the bone defect. Huang et al. (2020) prepared a novel composite $\mathrm{CaCO}_{3} / \mathrm{MgO} / \mathrm{CMC} / \mathrm{BMP} 2$ scaffold with high mechanical strength, mineralization ability, biomimetic activity and osteogenic differentiation. The sustainable release of $\mathrm{Mg}^{2+}$ and BMP2 played an important role in activating the phosphorylation of ERK1/2 and Akt pathways, which guided the osteogenesis formation using an in-situ rat calvarial defect model (Figure 6).

\section{CS-Based Hydrogels for Dental Repair Periodontal Regeneration}

Periodontitis is a chronic inflammation of periodontal support tissues caused by the local bacterial infection. The age of onset was after 35 years old. If gingivitis is not treated in time, the inflammation can spread from gingival to the periodontal membrane and alveolar bone, thus forming the periodontitis. Due to no obvious conscious symptoms and easy to be ignored at initial stage, once the symptoms are more serious, treatment of such pathology is a great challenge for the clinician (Cortellini and Tonetti, 2015; Larsson et al., 2015; Kinane et al., 2017; Roi et al., 2019; Xu et al., 2020a,b). In general, reducing the inflammation is a key to control the infection for periodontal therapy, but traditional mechanical treatments like scaling and root planin are closely connected with the wound repair. In addition, non-surgical treatment alone is insufficient for adjuvant therapy (Abdul Rahman et al., 2019; Harmouche et al., 2019). Therefore, use of local delivery of active drugs has been utilized as an effective strategy to address the inflammation and promote tissue repair (Morand et al., 2017; Batool et al., 2018; Petit et al., 2019). By means of the injectable chitosan hydrogels with modulable physico-chemical properties, CS-based delivery system can be employed as reliable vehicle to release the encapsulated active drugs (e.g., statins, doxycycline, antibiotics, and antiseptics) at the disease site within periodontal pockets (Özdoğan et al., 2018). Simultaneous anti-inflammation and periodontium regeneration is vital for terminating the alveolar bone resorption. Based on this, Xu et al. (2019) proposed a thermo-responsive CS-based injectable hydrogel with the main components of CS, $\beta$-sodium glycerophosphate $(\beta$-GP) and gelatin. After tailoring the continuous release behavior of aspirin (ASP) and erythropoietin (EPO), CS/ $\beta$-GP/gelatin@ASP/EPO scaffolds exerted pharmacological roles of anti-inflammation and periodontium regeneration, indicating the suitable candidate for dental treatment in the clinical fields (Figure 7). Zang et al. (2019) also prepared a thermo-sensitive bone morphogenetic protein-7 (BMP-7) and ornidazole (ORN)-encapsulated CS/ $\beta$-GP composite hydrogel. The BMP-7 and ORN molecules could be stably and sustainably released from the hydrogels, displaying the significantly antimicrobial activity and improved osteoclasts ability than that of control groups. The results indicated 


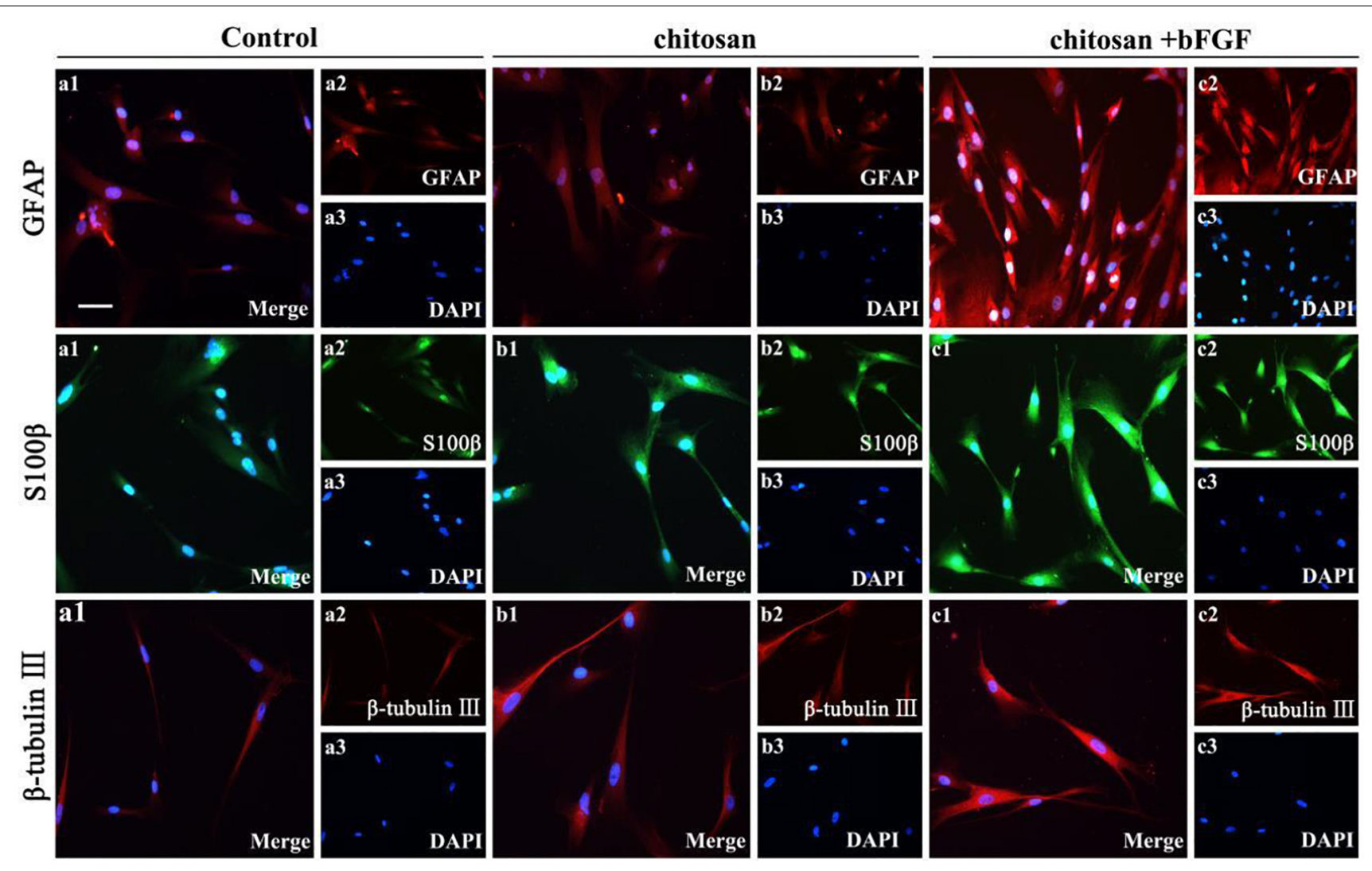

FIGURE 7 | Schematic illustration of the preparation and application of the CS/ $\beta$-GP/gelatin hydrogels. Reproduced from Xu et al. (2019) with permission from Copyright 2019 Elsevier.

that $\mathrm{CS} / \beta$-GP hydrogels with the controllable delivery of BMP-7 and ORN were valuable and promising for the periodontal therapy.

\section{Dental-Pulp Regeneration}

Dental-pulp mainly consists of nerves, blood vessels, lymph and connective tissue, as well as odontoid cells lining periphery of the pulp, aiming to form dentin with the ability of nutrition, feeling and defense. The pulp nerve is particularly sensitive to external stimuli and can produce unbearable pain. In general, dental-pulp regeneration strategy aim to achieve the regeneration of connective tissue, dentin tooth root edification, vascularization and innervation (Keller et al., 2015). Based on the smart drug delivery system, hydrogels are used to deliver active molecules and carry competent cells within the endodontic compartment for the endodontic treatment, which required adequate viscosity and injectable nature of hydrogels to quick adhesion and gelation in the whole root canal system. Recently, it is reported that CS-based hydrogels are widely developed for dental-pulp regeneration, because they can promote proliferation, migration and odontoblastic differentiation of dental pulp stem cells (DPSCs) and MSCs both in vitro and in vivo (Bordini et al., 2019; Ducret et al., 2019; Zhu N. et al., 2019). For example, Zhang et al. found that when the DPSCs were cultured in CS-based hydrogels containing basic fibroblast growth factor (bFGF) for
7 days, GFAP, S100 $\beta$ and $\beta$-tubulin III levels were significantly increased than the control and pure chitosan groups, indicating the non-toxic CS hydrogels carry and transport the therapeutic cells effectively to the recipient area and great potential for the DPSCs survival and dental-pulp regeneration (Figure 8; Zheng et al., 2020).

It is well-known that VEGF plays a crucial role in reparative dentin formation, whereas its constant administrations remains problematic within the body. Wu et al. (2019) conducted a VEGF-loaded injectable CS/ $\beta$-GP composite hydrogel with a sustained drug release behavior. After cultured DPSCs with CS/ $\beta$-GP hydrogel, CCK- 8 assay found that DPSCs could keep cell adhesion and proliferation activity. Along with the continual release of VEGF from the VEGF/CS/ $\beta$-GP hydrogel, odontogenic differentiation capacities were significantly improved, which could be utilized as an ideal drug carrier for the pulp capping therapy.

\section{FUTURE OUTLOOK AND CONCLUSION}

Chitosan, a deacetylated form of chitin, is widely utilized as a positive-charged and low-cost natural polymer for bone and dental tissue engineering applications. On account of the excellent biocompatibility, good biodegradability and 


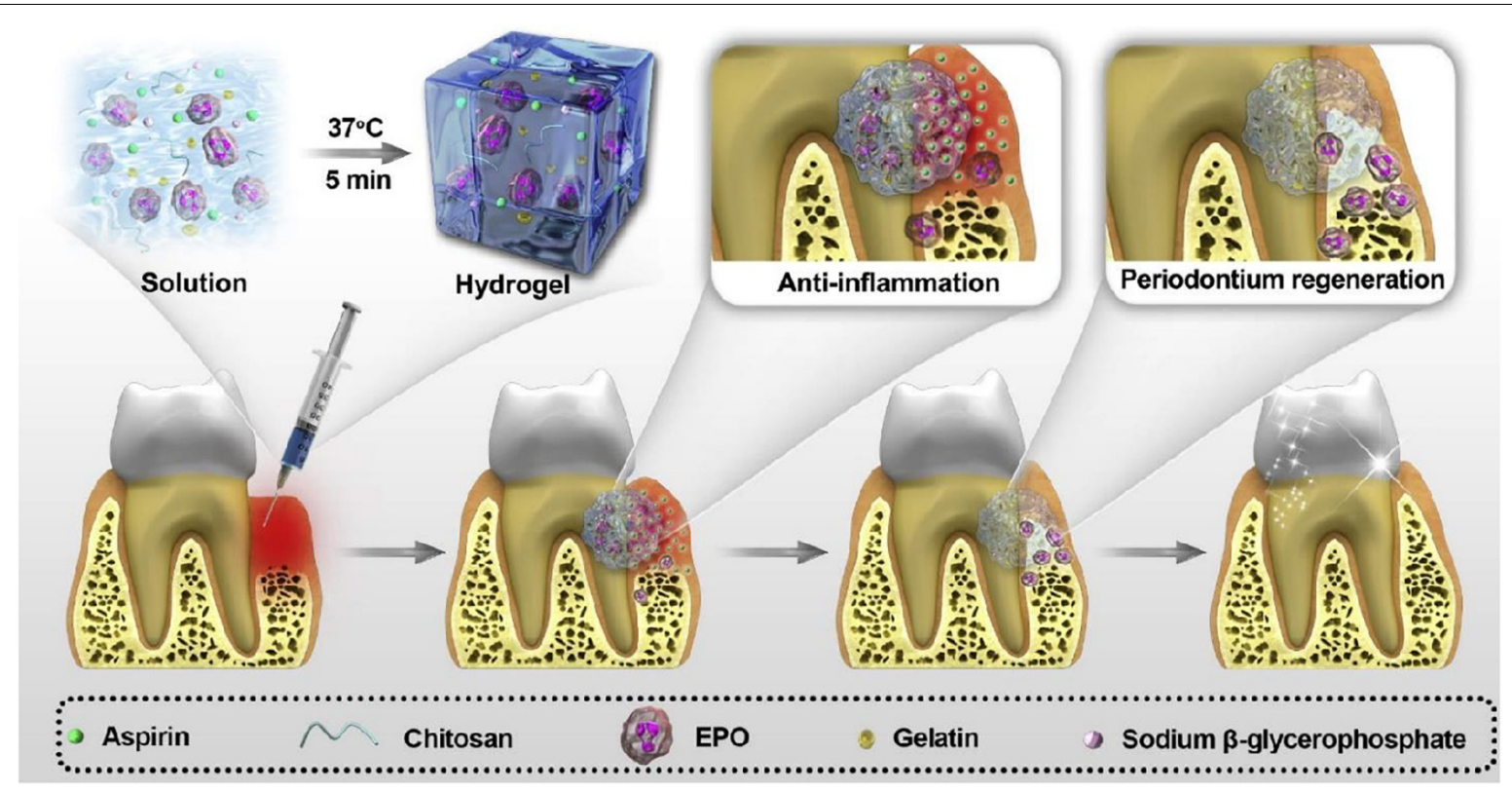

FIGURE 8 | Effect of chitosan/bFGF scaffolds on neural differentiation of DPSCs. Immunofluorescence staining of GFAP, S100 $\beta$ and $\beta$-tubulin III. Reproduced from Zheng et al. (2020) with permission from Copyright 2020 Informa Healthcare.

adjustable physico-chemical properties, in this review, we briefly summarized the various physio-chemical properties of CS-based injectable hydrogels for bone repair and explored in depth the updated progress of CS-based hydrogels with more innate advantages to promote cell attachment, spreading, proliferation and differentiation, thus benefiting for the tissue repair and regenerative medicine for the last two decades. To improve the mechanical characteristics, physicochemical and biological properties, CS-based hydrogels are required to combine with other natural or synthetic polymers, which can create a series of environmentally responsive and injectable hydrogels for biomedical engineering applications. In addition, incorporation of bioactive molecules with CS-based hydrogels can induce the angiogenesis and vascularization, accelerate bone repair and promote periodontal tissue engineering. We believe that further research on chitosan and the search for new variations in its use with other polymers will reveal greater prospects in biomedical applications.

Although CS-based hydrogels are possible alternative for current clinical practices of bone defect repair with vast array of beneficial properties, there is some clinical limitation for bone and dental regeneration. One major limitation is the standardization of molecular weight distribution, raw material resources and commercial production. High molecular weight may cause potential inflammation as a bone graft, and cell wall-derived CS may be more reliable than that from seafood due to the varieties and reproducibility of fungal and marine sources all over the world. In addition, CS-based hydrogels as bone scaffolds are their infancy in experimental research with limited studies and insufficient clinical utility. Therefore, further research should be focused on the establishment of uniform standards and invention of advanced technology to expand potential clinical applications. Additionally, improvement of higher loading capacity and controlled release of bioactive molecules into CS-based hydrogels will be a prime research objective upon implantation for clinical applications. Going forward clinical research is the combination of CS-based hydrogels with different biofabrication techniques like electrospinning, microspheres and 3D-printing for building a multifaceted and multilayered bone graft in bone regeneration and fracture management.

Thus, we believed that along with clear elucidation of the molecular and signaling mechanisms on bone and dental regeneration, CS-based hydrogels will spark broader interests in the scientific community to create more tailormade tissueengineering scaffolds with optimum characteristics and advanced properties like natural bones to combat large bone defects in clinical therapeutics.

\section{AUTHOR CONTRIBUTIONS}

RC, XW, and XY initiated the project. GT, ZT, WZ, CS, YL, and $\mathrm{HH}$ searched the data base. GT, XW, and XY wrote, revised, and finalized the manuscript. All authors contributed to the article and approved the submitted version.

\section{FUNDING}

This work was supported by the National Natural Science Foundation of China (51973226 and 81772445), and the Hunan Province Science and Technology Department (2017SK51001). 


\section{REFERENCES}

Abdul Rahman, N., Nickles, K., Gallenbach, K., Dannewitz, B., Ramich, T., and Scharf, S., et al. (2019). Five-year stability of clinical attachment after regenerative treatment of infrabony defects compared to controls. J. Clin. Periodontol. 46, 650-658.

Akilbekova, D., Shaimerdenova, M., Adilov, S., and Berillo, D. (2018). Biocompatible scaffolds based on natural polymers for regenerative medicine. Int. J. Biol. Macromol. 114, 324-333. doi: 10.1016/j.ijbiomac.2018.03.116

Amin, S., Achenbach, S. J., Atkinson, E. J., Khosla, S., and Melton, I. I. I. L. J. (2014). Trends in fracture incidence: a population-based study over 20 years. J. Bone Miner. Res. 29:581. doi: 10.1002/jbmr.2072

Amini, A. R., Laurencin, C. T., and Nukavarapu, S. P. (2012). Bone tissue engineering: recent advances and challenges. Crit. Rev. Biomed. Eng. 40, $363-$ 408. doi: 10.1615/critrevbiomedeng.v40.i5.10

Argüelles-monal, W. M., Lizardi-mendoza, J., Daniel, F. Q., and Montielherrera, M. (2018). Chitosan derivatives: introducing new functionalities with a controlled molecular architecture for innovative materials. Polymers 10:342. doi: 10.3390/polym10030342

Arvidson, K., Abdallah, B. M., Applegate, L. A., Baldini, N., Cenni, E., GomezBarrena, E., et al. (2011). Bone regeneration and stem cells. J. Cell Mol. Med. 15, 718-746.

Atak, B. H., Buyuk, B., Huysal, M., Isik, S., Senel, M., Metzger, W., et al. (2017). Preparation and characterization of amine functional nanohydroxyapatite/chitosan bionanocomposite for bone tissue engineering applications. Carbohydr. Polym. 164, 200-213. doi: 10.1016/j.carbpol.2017. 01.100

Bagheri, B., Zarrintaj, P., Samadi, A., Zarrintaj, R., Ganjali, M. R., Saeb, M. R., et al. (2020). Tissue engineering with electrospun electro-responsive chitosananiline oligomer/polyvinyl alcohol. Int. J. Biol. Macromol. 147, 160-169. doi: 10.1016/j.ijbiomac.2019.12.264

Bagheri, B., Zarrintaj, P., Surwase, S. S., Baheiraei, B., Saeb, M. R., Mozafari, M., et al. (2019). Self-gelling electroactive hydrogels based on chitosan-aniline oligomers/agarose for neural tissue engineering with on-demand drug release. Coll. Surf. B 184:110549. doi: 10.1016/j.colsurfb.2019.110549

Baldwin, P., Li, D. J., Auston, D. A., Mir, H. S., Yoon, R. S., and Koval, K. J. (2019). Autograft, allograft, and bone graft substitutes: clinical evidence and indications for use in the setting of orthopaedic trauma surgery. J. Orthop. Trauma 33, 203-213. doi: 10.1097/bot.0000000000001420

Bao, W. R., Li, M. L., Yang, Y. Y., Wan, Y., Wang, X., Bi, N., et al. (2020). Advancements and frontiers in high performance of natural hydrogels for cartilage tissue engineering. Front. Chem. 8:53. doi: 10.3389/fchem.2020.00053

Bao, W. R., Lyu, J. R., Li, C. L., Zhang, J. F., Sun, T. N., Wang, X., et al. (2019). Fabrication of customized nanogel carriers from a UV-triggered dynamic self-assembly strategy. Front. Chem. 7:769. doi: 10.3389/fchem.2020.00769

Batool, F., Strub, M., Petit, C., Bugueno, I. M., Bornert, F., Clauss, F., et al. (2018). Periodontal tissues, maxillary jaw bone, and tooth regeneration approaches: from animal models analyses to clinical applications. Nanomaterials 8:337. doi: 10.3390/nano8050337

Berger, J., Reist, M., Mayer, J. M., Felt, O., and Gurny, R. (2004). Structure and interactions in chitosan hydrogels formed by complexation or aggregation for biomedical applications. Eur. J. Pharm. Biopharm. 57, 35-52. doi: 10.1016/ s0939-6411(03)00160-7

Berillo, D., and Cundy, A. (2018). 3D-macroporous chitosan-based scaffolds with in situ formed Pd and Pt nanoparticles for nitrophenol reduction. Carbohydr. Polym. 192, 166-175. doi: 10.1016/j.carbpol.2018.03.038

Berillo, D., Elowsson, L., and Kirsebom, H. (2012). Oxidized dextran as crosslinker for chitosan cryogel scaffolds and formation of polyelectrolyte complexes between chitosan and gelatin. Macromol. Biosci. 12, 1090-1099. doi: 10.1002/ mabi.201200023

Berillo, D., Mattiasson, B., and Kirsebom, H. (2014). Cryogelation of chitosan using noble-metal ions: in situ formation of nanoparticles. Biomacromolecules 15, 2246-2255. doi: 10.1021/bm5003834

Bian, J., Xia, Y. X., Sang, L. Y., Zhu, C. X., Li, Y. X., Li, G. Y., et al. (2020). A recyclable colorimetric probe: in-situ fabrication of highly stable HPEIAuNPs for selective Ag+ detection. New J. Chem. 44, 5438-5447. doi: 10.1039/ d0nj00497a
Bordini, E. A. F., Cassiano, F. B., Silva, I. S. P., Usberti, F. R., Anovazzi, G., Pacheco, L. E., et al. (2019). Synergistic potential of 1 $\alpha, 25$-dihydroxyvitamin D3 and calcium-aluminate-chitosan scaffolds with dental pulp cells. Clin. Oral Investig. 24, 663-674. doi: 10.1007/s00784-019-02906-z

Cao, Q. C., Wang, X., and Wu, D. C. (2018). Controlled cross-linking strategy for formation of hydrogels, microgels and nanogels. Chin. J. Polym. Sci. 36, 8-17. doi: 10.1007/s10118-018-2061-7

Chen, J. P., Tsai, M. J., and Liao, H. T. (2013). Incorporation of biphasic calcium phosphate microparticles in injectable thermoresponsive hydrogel modulates bone cell proliferation and differentiation. Colloids Surf. B 110, 120-129. doi: 10.1016/j.colsurfb.2013.04.028

Chen, Y. C., Wang, C. H., Lai, L. S., and Lin, K. W. (2003). Rheological properties of chitosan Chenite and its interaction with porcine myofibrillar proteins as influenced by chitosan's degree of deacetylation and concentration. J. Food Sci. 68, 826-831. doi: 10.1111/j.1365-2621.2003.tb08250.x

Chen, Y. R., Zhou, Z. X., Zhang, J. Y., Yuan, F. Z., Xu, B. B., Guan, J., et al. (2019). Low-molecular-weight heparin-functionalized chitosan-chondroitin sulfate hydrogels for controlled release of TGF- $\beta 3$ and in vitro neocartilage formation. Front. Chem. 7:745. doi: 10.3389/fchem.2020.00745

Chenite, A., Buschmann, M., Wang, D., Chaput, C., and Kandani, N. (2001). Rheological characterisation of thermogelling chitosan/glycerol-phosphate solutions. Carbohydr. Polym. 46, 39-47. doi: 10.1016/s0144-8617(00)00281-2

Cortellini, P., and Tonetti, M. S. (2015). Clinical concepts for regenerative therapy in intrabony defects. Periodontol. 68, 282-307. doi: 10.1111/prd.12048

Deepthi, S., Venkatesan, J., Kim, S. K., Bumgardner, J. D., and Jayakumar, R. (2016). An overview of chitin or chitosan/nano ceramic composite scaffolds for bone tissue engineering. Int. J. Biol. Macromol. 93, 1338-1353. doi: 10.1016/j. ijbiomac.2016.03.041

Dhivya, S., Saravanan, S., Sastry, T. P., and Selvamurugan, N. (2015). Nanohydroxyapatite-reinforced chitosan composite hydrogel for bone tissue repair in vitro and in vivo. J. Nanobiotech. 13:40.

Ducret, M., Montembault, A., Josse, J., Pasdeloup, M., Celle, A., Benchrih, R., et al. (2019). Design and characterization of a chitosan-enriched fibrin hydrogel for human dental pulp regeneration. Dent. Mater. 35, 523-533. doi: 10.1016/j. dental.2019.01.018

El-hefian, E. A., and Yahaya, A. H. (2010). Rheological study of chitosan and its blends: an overview. Maejo Int. J. Sci. Tech. 4, 210-220.

Faikrua, A., Wittaya-areekul, S., Oonkhanond, B., and Viyoch, J. (2014). A thermosensitive chitosan/corn starch/ $\beta$-glycerol phosphate hydrogel containing TGF- $\beta 1$ promotes differentiation of MSCs into chondrocyte-like cells. Tis. Eng. Reg. Med. 11, 355-361. doi: 10.1007/s13770-014-0030-y

Fan, D. Y., Wang, Q., Zhu, T. J., Wang, H. F., Liu, B. C., Wang, Y. F., et al. (2020). Recent advances of magnetic nanomaterials in bone tissue repair. Front. Chem. 8:124. doi: 10.3389/fchem.2020.00124

Fan, L. F., Wang, X., Cao, C. Q., Yang, Y. Y., and Wu, D. C. (2019). POSSbased supramolecular amphiphilic zwitterionic complexes for drug delivery. Biomater. Sci. 7, 1984-1994. doi: 10.1039/c9bm00125e

Gómez-Barrena, E., Rosset, P., Lozano, D., Stanovici, J., Ermthaller, C., and Gerbhard, F. (2015). Bone fracture healing: cell therapy in delayed unions and nonunions. Bone 70, 93-101. doi: 10.1016/j.bone.2014.07.033

Guo, B., and Ma, P. X. (2014). Synthetic biodegradable functional polymers for tissue engineering: a brief review. Sci. China Chem. 57, 490-500. doi: 10.1007/ s11426-014-5086-y

Gyawali, D., Nair, P., Kim, H. K., and Yang, J. (2013). Citrate-based biodegradable injectable hydrogel composites for orthopedic applications. Biomater. Sci. 1, 52-64. doi: 10.1039/c2bm00026a

Harmouche, L., Courval, A., Mathieu, A., Petit, C., Huck, O., Severac, F., et al. (2019). Impact of tooth-related factors on photodynamic therapy effectiveness during active periodontal therapy: a 6-months split-mouth randomized clinical trial. Photodiagnosis Photodyn. 27, 190-194.

Hench, L. L., and Polak, J. M. (2002). Third-generation biomedical materials. Science 295, 1014-1017. doi: 10.1126/science.1067404

Hennink, W. E., and van Nostrum, C. F. (2012). Novel crosslinking methods to design hydrogels. Adv. Drug Delivery Rev. 64, 223-236. doi: 10.1016/j.addr. 2012.09.009

Hoffman, A. S. (2012). Hydrogels for biomedical applications. Adv. Drug Deliv. Rev. 64, 18-23. 
Hu, J. L., Hou, Y. P., Park, H., Choi, B., Hou, S. Y., Chung, A., et al. (2012). Visible light crosslinkable chitosan hydrogels for tissue engineering. Acta Biomater. 8, 1730-1738. doi: 10.1016/j.actbio.2012.01.029

Huang, Y. Z., Ji, Y. R., Kang, Z. W., Li, F., Ge, S. F., Yang, D. P., et al. (2020). Integrating eggshell-derived $\mathrm{CaCO} / \mathrm{MgO}$ nanocomposites and chitosan into a biomimetic scaffold for bone regeneration. Chem. Eng. J. 395:125098. doi: 10.1016/j.cej.2020.125098

Hwang, J. K., and Shin, H. H. (2000). Rheological properties of chitosan solutions. Korea Aust. Rheol. J. 12, 175-179.

Jiang, T., Ji, H., Zhang, L., Wang, Y., and Zhou, H. (2019). Chitosan oligosaccharide exerts anti-allergic effect against shrimp tropomyosin-induced food allergy by affecting Th1 and Th2 cytokines. Int. Arch. Allergy Immunol. 180, 10-16. doi: 10.1159/000500720

Kavya, K. C., Jayakumar, R., Nair, S., and Chennazhi, K. P. (2013). Fabrication and characterization of chitosan/gelatin/nSiO2 composite scaffold for bone tissue engineering. Int. J. Biol. Macromol. 59, 255-263. doi: 10.1016/j.ijbiomac.2013. 04.023

Keller, L., Offner, D., Schwinté, P., Morand, D., Wagner, Q., Gros, C., et al. (2015). Active nanomaterials to meet the challenge of dental pulp regeneration. Materials 8, 7461-7471. doi: 10.3390/ma8115387

Keller, L., Regiel-Futyra, A., Gimeno, M., Eap, S., Mendoza, G., Andreu, V., et al. (2017). Chitosan-based nanocomposites for the repair of bone defects. Nanomedicine 13, 2231-2240. doi: 10.1016/j.nano.2017.06.007

Khalili, R., Zarrintaj, P., Jafari, S. H., Vahabi, H., and Saeb, M. R. (2020). Electroactive poly (p-phenylene sulfide)/r-Graphene Oxide/Chitosan as a novel potential candidate for tissue engineering. Int. J. Biol. Macromol. 154, 18-24. doi: 10.1016/j.ijbiomac.2020.03.029

Kinane, D. F., Stathopoulou, P. G., and Papapanou, P. N. (2017). Periodontal diseases. Nat. Rev. Dis. Primers 3:17038.

Ko, D. Y., Shinde, U. P., Yeon, B., and Jeong, B. (2013). Recent progress of in situ formed gels for biomedical applications. Prog. Polym. Sci. 38, 672-701. doi: 10.1016/j.progpolymsci.2012.08.002

Ko, W., Lee, J. S., and Hwang, Y. (2018). Injectable hydrogel composite containing modified gold nanoparticles: implication in bone tissue regeneration. Int. J. Nanomed. 13, 7019-7031. doi: 10.2147/ijn.s185715

Larsson, L., Decker, A., Nibali, L., Pilipchuk, S., Berglundh, T., and Giannobile, W. V. (2015). Regenerative medicine for periodontal and peri-implant diseases. J. Dent. Res. 95, 255-266. doi: 10.1177/0022034515618887

Lavanya, K., Viji Chandran, S., Balagangadharan, K., and Selvamurugan, N. (2020). Temperature- and $\mathrm{pH}$-responsive chitosan-based injectable hydrogels for bone tissue engineering. Mater. Sci. Eng. C 111:110862. doi: 10.1016/j.msec.2020. 110862

Lewandowska, K. (2009). Rheological properties of chitosan acetate blends with vinyl polymers. Prog. Chem. Appl. Chitin Dravit. 14, 41-48.

Li, B. Q., Wang, L., Xu, F., Gang, X. M., Demirci, U., Wei, D. Q., et al. (2015). Hydrosoluble, UV-crosslinkable and injectable chitosan for patterned cell-laden microgel and rapid transdermal curing hydrogel in vivo. Acta Biomater. 22, 59-69. doi: 10.1016/j.actbio.2015.04.026

Li, D. W., Chen, J., Wang, X., Zhang, M. M., Li, C. L., and Zhou, J. (2020a). Recent advances on synthetic and polysaccharide adhesives for biological hemostatic applications. Front. Bioeng. Biotechnol. 8:926. doi: 10.3389/fbioe.2020.00926

Li, D. W., Zhou, J., Zhang, M. M., Ma, Y. Z., Yang, Y. Y., Han, X., et al. (2020b). Long-term delivery of alendronate through injectable tetra-PEG hydrogel to promote osteoporosis therapy. Biomater. Sci. 8, 3138-3146. doi: 10.1039/ d0bm00376j

Li, H., Ji, Q., Chen, X., Sun, Y., Xu, Q., Deng, P., et al. (2017). Accelerated bony defect healing based on chitosan thermosensitive hydrogel scaffolds embedded with chitosan nanoparticles for the delivery of BMP2 plasmid DNA. J. Biomed. Mat. Res. A 105, 265-273. doi: 10.1002/jbm.a.35900

Li, X., Sun, Q., Li, Q., Kawazoe, N., and Chen, G. (2018). Functional hydrogels with tunable structures and properties for tissue engineering applications. Front. Chem. 6:499. doi: 10.3389/fchem.2020.00499

Liu, H. Y., Wang, X., Cao, Y. X., Yang, Y. Y., Yang, Y. T., Gao, Y. F., et al. (2020). Freezing-tolerant, highly sensitive strain and pressure sensors assembled from ionic conductive hydrogels with dynamic cross-links. ACS Appl. Mater. Interf. 12, 25334-25344. doi: 10.1021/acsami.0c06067

Liu, B. C., Zhao, Y. R., Zhu, T. J., Gao, S., Ye, K. F., Zhou, F., et al. (2020). Biphasic double-network hydrogel with compartmentalized loading of bioactive glass for osteochondral defect repair. Front. Bioeng. Biotechnol. 8:752. doi: 10.3389/ fchem.2020.00752

Liu, M., Zeng, X., Ma, C., Yi, H., Ali, Z., Mou, X., et al. (2017). Injectable hydrogels for cartilage and bone tissue engineering. Bone Res. 5:17014.

Loi, F., Córdova, L. A., Pajarinen, J., Lin, T., Yao, Z., and Goodman, S. B. (2016). Inflammation, fracture and bone repair. Bone 86, 119-130. doi: 10.1016/j.bone. 2016.02.020

Lu, H. T., Lu, T. W., Chen, C. H., Lu, K. Y., and Mi, F. L. (2018). Development of nanocomposite scaffolds based on biomineralization of N,O-carboxymethyl chitosan/fucoidan conjugates for bone tissue engineering. Int. J. Biol. Macromol. 120, 2335-2345. doi: 10.1016/j.ijbiomac.2018.08.179

Mahmodi, G., Zarrintaj, P., Taghizadeh, A., Taghizadeh, M., Manouchehri, S., Dangwal, S., et al. (2020). From microporous to mesoporous mineral frameworks: An alliance between zeolite and chitosan. Carbohyd. Res. 489:107930. doi: 10.1016/j.carres.2020.107930

Maitra, J., and Shukla, V. K. (2014). Cross-linking in hydrogels-a review. Am. J. Polym. Sci. 4, 25-31.

Martiínez, A., Chornet, E., and Rodrigue, D. (2004). Steady-shear rheology of concentrated chitosan solutions. J. Texture Stud. 35, 53-74. doi: 10.1111/j.17454603.2004.tb00822.x

Menon, A. H., Soundarya, S. P., Sanjay, V., Chandran, S. V., Balagangadharan, K., and Selvamurugan, N. (2018). Sustained release of chrysin from chitosanbased scaffolds promotes mesenchymal stem cell proliferation and osteoblast differentiation. Carbohydr. Polym. 195, 356-367. doi: 10.1016/j.carbpol.2018. 04.115

Mi, L., Liu, H., Gao, Y., Miao, H., and Ruan, J. (2017). Injectable nanoparticles/hydrogels composite as sustained release system with stromal cell-derived factor-1 $\alpha$ for calvarial bone regeneration. Int. J. Biol. Macromol. 101, 341-347. doi: 10.1016/j.ijbiomac.2017.03.098

Min, J. H., Patel, M., and Koh, W. (2018). Incorporation of conductive materials into hydrogels for tissue engineering applications. Polymers 10:1078. doi: 10. 3390/polym 10101078

Mohebbi, S., Nezhad, M. N., Zarrintaj, P., Jafari, S. H., Gholizadeh, S. S., Saeb, M. R., et al. (2019). Chitosan in biomedical engineering: a critical review. Curr. Stem Cell Res. Trans. 14, 93-116. doi: 10.2174/1574888x13666180912142028

Moorthi, A., Parihar, P. R., Saravanan, S., Vairamani, M., and Selvamurugan, N. (2014). Effects of silica and calcium levels in nanobioglass ceramic particles on osteoblast proliferation. Mater. Sci. Eng. C. 43, 458-464. doi: 10.1016/j.msec. 2014.07.040

Morand, D. N., Davideau, J. L., Clauss, F., Jessel, N., Tenenbaum, H., and Huck, O. (2017). Cytokines during periodontal wound healing: potential application for new therapeutic approach. Oral Dis. 23, 300-311. doi: 10.1111/odi.12469

Moreira, C. D., Carvalho, S. M., Sousa, R. G., Mansur, H. S., and Pereira, M. M. (2018). Nanostructured chitosan/gelatin/bioactive glass in situ forming hydrogel composites as a potential injectable matrix for bone tissue engineering. Mater. Chem. Phys. 218, 304-316. doi: 10.1016/j.matchemphys.2018. 07.039

Moreira, C. D. F., Carvalho, S. M., Florentino, R. M., França, A., Okano, B. S., Rezende, C. M. F., et al. (2019). Injectable chitosan/gelatin/bioactive glass nanocomposite hydrogels for potential bone regeneration: in vitro and in vivo analyses. Int. J. Biol. Macromol. 132, 811-821. doi: 10.1016/j.ijbiomac.2019. 03.237

Nafee, N., Zewail, M., and Boraie, N. (2017). Alendronate-loadedbiodegradable smart hydrogel: a promising injectable depot formulation for osteoporosis. J. Drug Target. 26, 563-575. doi: 10.1080/1061186x.2017.1390670

Ngo, D. H., and Kim, S. K. (2014). Antioxidant effects of chitin, chitosan, and their derivatives. Adv. Food Nutr. Res. 73, 15-31.

Nourbakhsh, M., Zarrintaj, P., Jafari, S. H., Hosseini, S. M., Aliakbari, S., Pourbadie, H. G., et al. (2020). Fabricating an electroactive injectable hydrogel based on pluronic-chitosan/aniline-pentamer containing angiogenic factor for functional repair of the hippocampus ischemia rat model. Mater. Sci. Eng. C 117:111328. doi: 10.1016/j.msec.2020.111328

Oudadesse, H., Najem, S., Mosbahi, S., Rocton, N., Refifi, J., El Feki, H., et al. (2020). Development of hybrid scaffold: Bioactive glass nanoparticles/chitosan for tissue engineering applications. J. Biomed. Mater. Res. A doi: 10.1002/jbm.a. 37043

Özdoğan, A. I., Ilarslan, Y. D., Kösemehmetŏglu, K., Akca, G., Kutlu, H. B., Comerdov, E., et al. (2018). In vivo evaluation of chitosan based local delivery 
systems for atorvastatin in treatment of periodontitis. Int. J. Pharm. 550, 470-476. doi: 10.1016/j.ijpharm.2018.08.058

Parhi, R. (2017). Cross-linked hydrogel for pharmaceutical applications: a review. Adv. Pharm. Bull. 7, 515-530. doi: 10.15171/apb.2017.064

Petit, C., Batool, F., Bugueno, I. M., Schwinté, P., Benkirane-Jessel, N., and Huck, O. (2019). Contribution of statins towards periodontal treatment: a review. Mediat. Inflamm. 2019:6367402.

Pourjavadi, A., Doroudian, M., Ahadpour, A., and Azari, S. (2019). Injectable chitosan/ $\kappa$-carrageenan hydrogel designed with au nanoparticles: a conductive scaffold for tissue engineering demands. Int. J. Biol. Macromol. 126, 310-317. doi: 10.1016/j.ijbiomac.2018.11.256

Qi, B. W., Yu, A. X., Zhu, S. B., Zhou, M., and Wu, G. (2013). Chitosan/poly (vinyl alcohol) hydrogel combined with Ad-hTGF- $\beta 1$ transfected mesenchymal stem cells to repair rabbit articular cartilage defects. Exper. Bio. Med. 238, 23-30. doi: 10.1258/ebm.2012.012223

Racine, L., Texiera, I., and Auzély-Veltyb, R. (2017). Chitosan-based hydrogels: recent design concepts to tailor properties and functions. Polym. Int. 66, 981-998. doi: 10.1002/pi.5331

Radwan, N. H., Nasr, M., Ishak, R. A. H., Abdeltawab, N. F., and Awad, G. A. S. (2020). Chitosan-calcium phosphate composite scaffolds for control of postoperative osteomyelitis: fabrication, characterization, and in vitro-in vivo evaluation. Carbohyr. Polym. 244:116482. doi: 10.1016/j.carbpol.2020.116482

Ran, J., Hu, J., Sun, G., Chen, S., Jiang, P., Shen, X., et al. (2016). A novel chitosantussah silk fibroin/nano-hydroxyapatite composite bone scaffold platform with tunable mechanical strength in a wide range. Int. J. Biol. Macromol. 93, 87-97. doi: 10.1016/j.ijbiomac.2016.08.062

Rizwan, M., Yahya, R., Hassan, A., Yar, M., Azzahari, A. D., Selvanathan, V., et al. (2017). pH sensitive hydrogels in drug delivery: brief history, properties, swelling and release mechanism. Mat. Select. Appl. 9:137. doi: 10.3390/ polym9040137

Rogina, A., Ressler, A., Matiæ, I., Ferrer, G. G., Marijanoviæ, I., Ivankoviæ, M., et al. (2017). Cellular hydrogels based on pH-responsive chitosan-hydroxyapatite system. Carbohydr. Polym. 166, 173-182. doi: 10.1016/j.carbpol.2017.02.105

Roi, A., Ardelean, L. C., Roi, C. I., Boia, E. R., Boia, S., and Rusu, L. C. (2019). Oral bone tissue engineering: advanced biomaterials for cell adhesion, proliferation and differentiation. Materials 12:2296. doi: 10.3390/ma12142296

Saravanan, S., Leena, R. S., and Selvamurugan, N. (2016). Chitosan based biocomposite scaffolds for bone tissue engineering. Int. J. Biol. Macromol. 93:1354. doi: 10.1016/j.ijbiomac.2016.01.112

Saravanan, S., Vimalraj, S., Thanikaivelan, P., Banudevi, S., and Manivasagam, G. (2019). A review on injectable chitosan/beta glycerophosphate hydrogels for bone tissue regeneration. Int. J. Biol. Macromol. 12, 38-54. doi: 10.1016/j. ijbiomac.2018.10.014

Shariatinia, Z., and Jalali, A. M. (2018). Chitosan-based hydrogels: preparation, properties and applications. Int. J. Biol. Macromol. 115, 194-220. doi: 10.1016/ j.ijbiomac.2018.04.034

Sivashanmugam, A., Arun Kumar, R., Vishnu Priya, M., Nair, S. V., and Jayakumar, R. (2015). An overview of injectable polymeric hydrogels for tissue engineering. Eur. Polym. J. 72, 543-565. doi: 10.1016/j.eurpolymj.2015.05.014

Stevens, M. M. (2008). Biomaterials for bone tissue engineering. Mater. Today 11, $18-25$.

Thoniyot, P., Tan, M. J., Karim, A. A., and Young, D. J. (2015). Nanoparticlehydrogel composites: concept, design, and applications of these promising, multi-functional materials. Adv. Sci. 2:1400010. doi: 10.1002/advs.201400010

Tiffany, N. V. O., Kasper, F. K., and Mikos, A. G. (2012). Strategies for controlled delivery of growth factors and cells for bone regeneration. Adv. Drug Deliv. Rev. 64, 1292-1309. doi: 10.1016/j.addr.2012.01.016

Visser, N. J., Rezaie, E. S., Friedrich, P. F., Kotsougiani, D., Shin, A. Y., and Bishop, A. T. (2019). Effects of surgical angiogenesis on segmental bone reconstruction with cryopreserved massive-structural allografts in a porcine tibia model. J. Orthop. Res. 37, 1698-1708. doi: 10.1002/jor.24318

Vo, T. N., Shah, S. R., Lu, S., Tatara, A. M., Lee, E. J., Roh, T. T., et al. (2016). Injectable dual-gelling cell-laden composite hydrogels for bone tissue engineering. Biomaterials 83, 1-11. doi: 10.1016/j.biomaterials.2015.12.026

Wang, S. J., Jiang, D., Zhang, Z. Z., Chen, Y. R., Yang, Z. D., Zhang, J. Y., et al. (2019). Biomimetic nanosilica-collagen scaffolds for in situ bone regeneration: toward a cell-free, one-step surgery. Adv. Mater. 31:1904341. doi: 10.1002/ adma.201904341
Wang, X., Gao, P. Y., Wang, J., Yang, Y. Y., You, Y. Z., and Wu, D. C. (2020a). A robust strategy for precise fabrication of rigid-flexible coupling dendrimers toward self-coordinated hierarchical assembly. CCS Chem. 2, 1093-1194. doi: 10.31635/ccschem.020.202000238

Wang, X., Gao, P. Y., Yang, Y. Y., Guo, H. X., and Wu, D. C. (2018a). Dynamic and programmable morphology and size evolution via a living hierarchical self-assembly strategy. Nat. Commun. 9:2772.

Wang, X., Li, D., Yang, F., Shen, H., Li, Z. B., and Wu, D. C. (2013). Controlled cross-linking strategy: from hybrid hydrogels to nanoparticle macroscopic aggregates. Polym. Chem. 4, 4596-4600. doi: 10.1039/c3py00811h

Wang, X., Wang, J., Yang, Y. Y., Yang, F., and Wu, D. C. (2017a). Fabrication of multi-stimuli responsive supramolecular hydrogels based on host-guest inclusion complexation of a tadpole-shaped cyclodextrin derivative with the azobenzene dimer. Polym. Chem. 8, 3901-3909. doi: 10.1039/c7py0 0698e

Wang, X., Yang, Y., Fan, L. F., Yang, F., and Wu, D. C. (2018b). POSS-embedded supramolecular hyperbranched polymers constructed from a $1 \rightarrow 7$ branching monomer with controllable morphology transitions. Sci. China Chem. 61, 311-318. doi: 10.1007/s11426-017-9168-3

Wang, X., Yang, Y. Y., Gao, P. Y., Li, D., Yang, F., Guo, H. X., et al. (2014). POSS dendrimers constructed from a $1 \rightarrow 7$ branching monomer. Chem. Commun. 50, 6126-6129. doi: 10.1039/c4cc01859a

Wang, X., Yang, Y. Y., Shi, Y., and Jia, F. (2020b). Editorial: smart hydrogels in tissue engineering and regenerative medicine. Front. Chem. 8:245. doi: 10.3389/ fchem.2020.00245

Wang, X., Yang, Y. Y., Yang, F., Shen, H., and Wu, D. C. (2017b). pHtriggered decomposition of polymeric fluorescent vesicles to induce growth of tetraphenylethylene nanoparticles for long-term live cell imaging. Polymer 118, 75-84. doi: 10.1016/j.polymer.2017.04.064

Wang, X., Yang, Y. Y., Zhuang, Y. P., Gao, P. Y., Yang, F., Shen, H., et al. (2016). Fabrication of $\mathrm{pH}$-responsive nanoparticles with an AIE feature for imaging intracellular drug delivery. Biomacromolecules 17, 2920-2929. doi: 10.1021/acs. biomac.6b00744

Wu, S., Zhou, Y. C., Yu, Y., Zhou, X., Du, W., Wan, M., et al. (2019). Evaluation of chitosan hydrogel for sustained delivery of VEGF for odontogenic differentiation of dental pulp stem cells. Stem Cells Int. 2019:1515040.

Wu, S. W., Liu, X., Miller, I. I. A. L., Cheng, Y. S., Yeh, M. L., and Lu, L. (2018). Strengthening injectable thermo-sensitive NIPAAm-g-chitosan hydrogels using chemical crosslinking of disulfide bonds as scaffolds for tissue engineering. Carbohydr. Polym. 192, 308-316. doi: 10.1016/j.carbpol.2018. 03.047

Xia, Y., Zhou, Y. S., Dong, Q., Yang, H. J., Liu, X., Gu, S. J., et al. (2017). Photopolymerized injectable water-soluble maleilated chitosan/poly(ethylene glycol) diacrylate hydrogels as potential tissue engineering scaffolds. J. Photopolym. Sci. Technol. 30, 33-40. doi: 10.2494/photopolymer.30.33

Xu, B. B., Ye, J., Yuan, F. Z., Zhang, J. Y., Chen, Y. R., Fan, B. S., et al. (2020a). Advances of stem cell-laden hydrogels with biomimetic microenvironment for osteochondral repair. Front. Bioeng. Biotechnol. 8:247. doi: 10.3389/fchem.2020. 00247

Xu, B. B., Yuan, F. Z., Lin, L., Ye, J., Fan, B. S., Zhang, J. Y., et al. (2020b). The higher inherent therapeutic potential of biomaterial-based hDPSCs and hEnSCs for pancreas diseases. Front. Bioeng. Biotechnol. 8:636. doi: 10.3389/fchem.2020. 00636

Xu, H. C., and Matysiak, S. (2017). Effect of pH on chitosan hydrogel polymer network structure. Chem. Commun. 53, 7373-7376. doi: 10.1039/c7cc01826f

Xu, X. W., Gu, Z. Y., Chen, X., Shi, C., Liu, C. W., Liu, M., et al. (2019). An injectable and thermosensitive hydrogel: promoting periodontal regeneration by controlled-release of aspirin and erythropoietin. Acta Biomater. 86, 235-246. doi: 10.1016/j.actbio.2019.01.001

Yang, J. A., Yeom, J., Hwang, B. W., Hoffman, A. S., and Hahn, S. K. (2014). In situforming injectable hydrogels for regenerative medicine. Prog. Polym. Sci. 39, 1973-1986. doi: 10.1016/j.progpolymsci.2014.07.006

Yang, Y. Y., Wang, X., Hu, Y., Hu, H., Wu, D. C., and Xu, F. J. (2014). Bioreducible POSS-based star-shaped polymer for efficient gene delivery. ACS Appl. Mater. Interf. 6, 1044-1052. doi: 10.1021/am404585d

Yang, Y. Y., Hu, H., Wang, X., Yang, F., Shen, H., Xu, F. J., et al. (2015). Acid-labile poly(glycidyl methacrylate)-based star gene vectors. ACS Appl. Mater. Interf. 7, 12238-12248. doi: 10.1021/acsami.5b02733 
Yang, Y. Y., Wang, X., Yang, F., Shen, H., and Wu, D. C. (2016). A universal soaking strategy to convert composite hydrogels into extremely tough and rapidly recoverable double-network hydrogels. Adv. Mater. 28, 7178-7184. doi: 10.1002/adma.201601742

Yang, Y. Y., Wang, X., Yang, F., Wang, L. N., and Wu, D. C. (2018). Highly elastic and ultratough hybrid ionic-covalent hydrogels with tunable structures and mechanics. Adv. Mater. 30:1707071. doi: 10.1002/adma.201707071

Yang, Y. Y., Yang, Y. T., Cao, X. Y., Wang, X., Chen, Y. R., Liu, H. Y., et al. (2021). Anti-freezing, resilient and tough hydrogels for sensitive and large-range strain and pressure sensors. Chem. Eng. J. 403:126431. doi: 10.1016/j.cej.2020.126431

Yu, T. T., Wang, H. F., Zhang, Y. F., Wang, X., and Han, B. (2020). The delivery of RNA-interference therapies based on engineered hydrogels for bone tissue regeneration. Front. Bioeng. Biotechnol. 8:445. doi: 10.3389/fchem.2020.00445

Zang, S. Q., Mu, R., Chen, F., Wei, X. C., Zhu, L., Han, B. Y., et al. (2019). Injectable chitosan/beta-glycerophosphate hydrogels with sustained release of BMP-7 and ornidazole in periodontal wound healing of class III furcation defects. Mater. Sci. Eng. C 99, 919-928. doi: 10.1016/j.msec.2019.02.024

Zarrintaj, P., Jouyandeh, M., Ganjali, M. R., Hadavand, B. S., Mozafari, M., Sheiko, S. S., et al. (2019). Thermo-sensitive polymers in medicine: a review. Eur. Polym. J. 117, 402-423.

Zhang, H., Zhang, F., and Wu, J. (2013). Physically crosslinked hydrogels from polysaccharides prepared by freeze-thaw technique. React. Funct. Polym. 73, 923-928. doi: 10.1016/j.reactfunctpolym.2012.12.014

Zhang, Y. H., Chen, M. J., Tian, J., Gu, P., Cao, H. L., Fan, X. Q., et al. (2019). In situ bone regeneration enabled by a biodegradable hybrid double-network hydrogel. Biomater. Sci. 7, 3266-3276. doi: 10.1039/c9bm00561g

Zhang, J. F., Luo, Z. P., Wang, W. J., Yang, Y. Y., Li, D. W., and Ma, Y. Z. (2019). One-pot synthesis of bio-functionally water-soluble POSS derivatives via efficient click chemistry methodology. React. Funct. Polym. 140, 103-110. doi: 10.1016/j.reactfunctpolym.2019.04.013

Zhao, C., Qazvini, N. T., Sadati, M., Zeng, Z., Huang, S., Losada, A., et al. (2019). A pH-triggered, self-assembled, and bioprintable hybrid hydrogel scaffold for mesenchymal stem cell-based bone tissue engineering. ACS Appl. Mater. Interf. 11, 8749-8762. doi: 10.1021/acsami.8b19094

Zheng, K., Feng, G. J., Zhang, J. L., Xing, J., Huang, D., Lian, M., et al. (2020). Basic fibroblast growth factor promotes human dental pulp stem cells cultured in 3D porous chitosan scaffolds to neural differentiation. Int. J. Neurosci. 5, 1-9. doi: 10.1080/00207454.2020.1744592

Zheng, L., Ao, Q., Han, H., Zhang, X., and Gong, Y. (2010). Evaluation of the chitosan/glycerol-betaphosphate disodium salt hydrogel application in peripheral nerve regeneration. Biomed. Mater. 5:35003.

Zhou, H. Y., Jiang, L. J., Cao, P. P., Li, J. B., and Chen, X. G. (2015). Glycerophosphate-based chitosan thermosensitive hydrogels and their biomedical applications. Carbohydr. Polym. 117, 524-536. doi: 10.1016/j.carbpol.2014.09.094

Zhu, N., Chatzistavrou, X., Ge, L., Qin, M., Papagerakis, P., and Wang, Y. (2019). Biological properties of modified bioactive glass on dental pulp cells. J. Dent. 83, 18-26. doi: 10.1016/j.jdent.2019.01.017

Zhu, C. X., Xia, Y. X., Zai, Y. Y., Dai, Y. Q., Liu, X. Y., Bian, J., et al. (2019). Adsorption and desorption behaviors of HPEI and thermoresponsive HPEI based gels on anionic and cationic dyes. Chem. Eng. J. 369:863. doi: 10.1016/ j.cej.2019.03.169

Conflict of Interest: The authors declare that the research was conducted in the absence of any commercial or financial relationships that could be construed as a potential conflict of interest.

Copyright (c) 2020 Tang, Tan, Zeng, Wang, Shi, Liu, He, Chen and Ye. This is an open-access article distributed under the terms of the Creative Commons Attribution License (CC BY). The use, distribution or reproduction in other forums is permitted, provided the original author(s) and the copyright owner(s) are credited and that the original publication in this journal is cited, in accordance with accepted academic practice. No use, distribution or reproduction is permitted which does not comply with these terms. 